\title{
Menentukan Aksi Karakter pada Game RPG dengan Logika Fuzzy Tsukamoto
}

\author{
Dhemma Ratanajaya*, Helmie Arif Wibawa \\ Program Studi Informatika \\ Universitas Diponegoro \\ Semarang \\ *ratanajayaa@gmail.com
}

\begin{abstract}
Abstrak-Turn-based Role Playing Game (RPG) adalah salah satu genre video game yang menggunakan sistem pertarungan antara dua kubu yang salah satunya dikontrol oleh pemain dan kubu lainnya oleh kecerdasan buatan. Pada RPG yang beredar di pasaran masih banyak game yang memiliki sistem kecerdasan buatan yang masih belum dapat mengambil keputusan yang paling baik untuk memenangkan pertarungan. Pada artikel ini dibahas tentang potongan dari game RPG yang didasarkan pada konvensi genre yang ditemukan pada game serupa. Setelah itu dibuat sistem kecerdasan buatan untuk mengontrol kubu musuh yang mampu melakukan pengambilan keputusan dengan tepat dalam pertarungan pada game tersebut. Logika furay digunakan pada sistem kecerdasan buatan sebagai fungsi untuk melakukan pembobotan atas pilihan keputusan yang dapat dilakukan. Sistem kecerdasan buatan akan menggunakan metode inferensi Tsukamoto dan metode defuzzifikasi centroid. Game dibuat menggunakan engine Unity3D dan bahasa pemrograman C\#. Proses pengembangan dilakukan dengan metode extremme programming. Hasil yang didapatkan menunjukkan bahwa implementasi logika fuгzy Tsukamoto dalam game RPG telah mampu mengoptimalkan game tersebut yaitu karakter dalam game mampu memilih aksi yang harus dilakukan terhadap target yang dihadapi.
\end{abstract}

Kata kunci: Game; RPG; Fuгzy Tsukamoto; Kecerdasan Buatan; Unity3D; Extremme Programming

\section{Pendahuluan}

Role Playing Game (RPG) adalah game yang pemainnya berperan sebagai seorang tokoh di dalam game, biasanya pada setting fantasi atau fiksi ilmiah, yang dapat berinteraksi dengan dunia di dalam game tersebut [1][2][3]. Genre ini adalah salah satu genre video game yang paling populer dan telah melahirkan beberapa sub-genre serta variasi regional seperti Japanese RPG (JRPG) dan Western RPG (WRPG).

Perbedaan utama antara JRPG dan WRPG terletak pada bagaimana battle atau pertarungan antara karakter pemain dan karakter musuh yang dikendalikan oleh komputer dilakukan. JRPG pada umumnya menggunakan turn-based battle system, yaitu sistem pertarungan antara dua kubu yang masing-masing kubu saling bergantian melakukan aksi dengan menunggu input dari pemain seperti permainan catur. Sedangkan WRPG pada umumnya menggunakan real-time battle system, yaitu sistem pertarungan yang setiap karakternya, baik karakter pemain ataupun karakter musuh melakukan aksi secara bersamaan [4].

Pada real-time battle, karakter musuh yang dikontrol oleh komputer memiliki keuntungan yang besar seperti akurasi yang sempurna dan kecepatan reaksi yang instan dibandingkan dengan karakter pemain yang dikontrol oleh manusia. Sehingga yang perlu diperhatikan dalam mendesain karakter musuh dalam game seperti ini adalah bagaimana membuatnya lebih mudah dikalahkan dengan memberikan sifat-sifat "manusiawi" seperti kemampuan untuk melakukan kesalahan. Namun lain halnya pada game turn-based. Kecepatan berpikir dan akurasi tidak diperhitungkan sehingga karakter pemain yang dikontrol oleh manusia dapat dengan mudah mengalahkan karakter musuh. Untuk menambah tantangan bagi pemain dalam game jenis turn-based ini, karakter musuh pada game perlu ditingkatkan kemampuannya. Karakter musuh yang dikontrol oleh komputer harus lebih mampu membaca keadaan lawan yang dikontrol oleh pemain. Selain itu karakter musuh harus mampu menentukan aksi yang harus dilakukan terkait kondisi lawan yang dihadapi. Oleh karena itu dibutuhkan sebuah kecerdasan buatan pada karakter musuh. Teknologi sekarang ini dapat digunakan untuk mendesain kecerdasan buatan game turn-based [5]. Logika fursy sebagai salah satu metode di dalam memberikan kecerdasan buatan pada karakter musuh yang mana dapat digunakan untuk mengontrol karakter dalam game [6]

Logika furay diperkenalkan pertama kali untuk pengembangan game pada 1996 pada Game Developer Magazine oleh Larry O’Brien dan sejak saat itu telah banyak dieksplorasi dan dikembangkan oleh pengembangpengembang lain. Bahkan Zarozinki menyatakan bahwa logika fursy selalu ada pada setiap game. Di dalam game, logika furzy pada umumnya diterapkan pada saat game atau karakter di dalam game perlu melakukan pengambilan keputusan berdasarkan data-data yang nilainya tidak tentu [7]. Shaout, et al. menggunakan model Mamdani untuk membuat ulang game Pac-Man [8] Demikian juga Li, menggunakannya pada pembuatan ulang game Battle City [9]. 
Dibandingkan dengan teknik-teknik lainnya, sistem pengambilan keputusan berbasis logika furay relatif mudah untuk didesain dan diimplementasikan. Output yang dihasilkannya tidak berbeda dengan sistem pengambilan keputusan berbasis data crisp. Perbedaannya hanyalah pada pada parameter atau input yang diterima, dan bagaimana mengolah input-input tersebut. Selain itu dari segi beban komputasi, logika furay juga termasuk cukup ringan. Pengolahan data input dilakukan dengan aritmatika sederhana dan jumlahnya pun proporsional dengan jumlah data input [9][10].

Salah satu model inferensi logika fuzzy adalah model Tsukamoto. Pada model ini proses inferensi dilakukan dengan mendefinisikan beberapa rules dengan masing-masing rule menggunakan dua atau lebih variabel. Pada setiap rule, nilai alfa diambil dari nilai minimum atau maksimum dari kedua variabel. Setelah itu dilakukan proses defuzifikasi dengan metode rata-rata terbobot. Jika dibandingkan dengan model inferensi lainnya, model Tsukamoto mempunyai kemampuan yang lebih tinggi dalam pengambilan keputuan untuk melakukan suatu tindakan [11]. Model Tsukamoto mempunyai output crisp sehingga pengaturan hubungan antar nilai input dan output menjadi lebih optimal yang mana akan sangat membantu dalam pengaturan karakter pada game [12]. Penggunaan model Tsukamoto telah memberikan hasil yang baik dalam penentuan kicking range pada game sepak takraw [12], demikian juga dalam menentukan posisi pemain sepak bola [13]. Oleh karena itu pada artikel ini dibahas tentang penggunaan model Tsukamoto untuk mengatur tindakan karakter pada game RPG sehingga karakter musuh dalam game mampu melakukan aksi yang lebih optimal.

\section{Metode}

\section{a. Desain Game}

Game ini terdiri dari tiga subsistem yaitu Sistem Pertarungan, Sistem Menu, dan Sistem Kecerdasan Buatan, dengan fungsinya masing-masing. Sistem Pertarungan berfungsi untuk mengatur jalannya pertarungan dalam game, Sistem Menu berfungsi untuk menjalankan antarmuka sebagai penghubung antara pemain dan Sistem Pertarungan, sedangkan Sistem Kecerdasan Buatan berfungsi untuk menjalankan kubu lawan. Alur sistem game ditujukkan pada gambar 1 .

Sebagaimana yang ditunjukkan pada Gambar 1. Pada saat pemain memulai game, scene pertama yang akan dihadapi adalah menu utama. Pemain dapat memasukkan parameter-parameter untuk menentukan state awal pertarungan yang meliputi karakter masing-masing kubu dan giliran pertama. Jika sudah selesai pemain dapat menekan tombol start untuk memulai pertarungan.

Pada battle scene pemain dan kecerdasan buatan dapat memberikan perintah aksi kepada sistem pertarungan pada gilirannya masing-masing. Setelah eksekusi setiap aksi akan dilakukan pengecekan apakah kubu lawan sudah kalah, jika ya game akan berhenti, pemain dapat memilih untuk kembali ke menu utama. Sedangkan jika tidak akan dilakukan pengecekan apakah giliran dari kubu yang sedang berjalan telah selesai jika ya ganti giliran, jika tidak tunggu input aksi dari karakter selanjutnya.

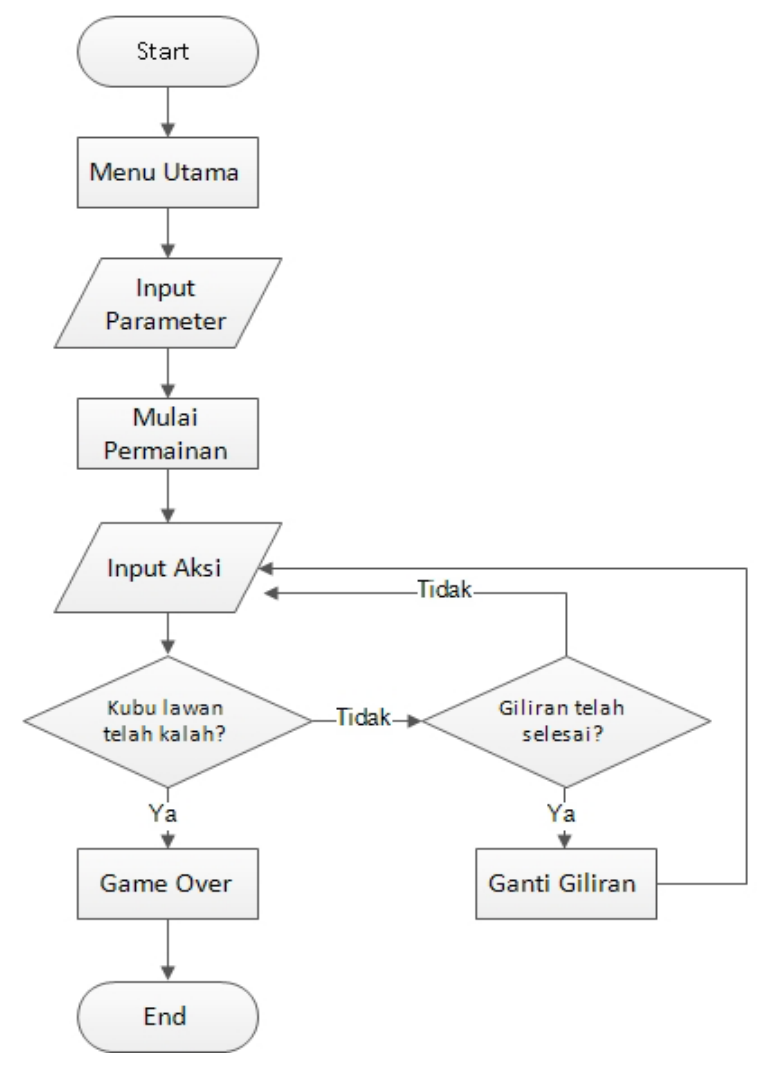

Gambar 1. Alur sistem game

Tabel 1. Data atribut

\begin{tabular}{|c|c|c|c|}
\hline Atribut & \multicolumn{2}{|c|}{ Arti } & Kegunaan \\
\hline $\mathrm{hp}$ & \multicolumn{2}{|c|}{ Health Point } & $\begin{array}{l}\text { Kemampuan karakter untuk bertahan } \\
\text { hidup }\end{array}$ \\
\hline ep & \multicolumn{2}{|c|}{ Energy Point } & $\begin{array}{l}\text { Kemampuan karakter untuk melakukan } \\
\text { aksi }\end{array}$ \\
\hline atk & \multicolumn{2}{|c|}{ Attack } & $\begin{array}{l}\text { Kekuatan karakter dalam melakukan } \\
\text { serangan fisik }\end{array}$ \\
\hline def & \multicolumn{2}{|c|}{ Defense } & $\begin{array}{l}\text { Pertahanan karakter terhadap serangan } \\
\text { fisik }\end{array}$ \\
\hline mag & \multicolumn{2}{|c|}{ Magic } & $\begin{array}{l}\text { Kekuatan karakter dalam melakukan } \\
\text { serangan mistis }\end{array}$ \\
\hline res & \multicolumn{2}{|c|}{ Resistance } & $\begin{array}{l}\text { Pertahanan karakter terhadap serangan } \\
\text { mistis }\end{array}$ \\
\hline actions & \multicolumn{2}{|c|}{ Actions } & $\begin{array}{l}\text { Aksi-aksi yang dapat dilakukan oleh } \\
\text { karakter }\end{array}$ \\
\hline \multicolumn{4}{|c|}{ Tabel 2. Definisi atribut } \\
\hline Aksi & Cost & Target & Fungsi \\
\hline Slash & 12 & Lawan & Mengurangi hp target \\
\hline Punch & 15 & Lawan & Mengurangi hp dan ep target \\
\hline Heal & 40 & Kawan & Menambah hp target \\
\hline Fire & 20 & Lawan & Mengurangi hp target \\
\hline Shoot & 15 & Lawan & Mengurangi hp target \\
\hline Guard & 0 & Kawan & $\begin{array}{l}\text { Menambah DEF dan RES target } \\
\text { sebanyak } 25 \% \text { untuk satu giliran }\end{array}$ \\
\hline
\end{tabular}


Tabel 3. Data aksi

\begin{tabular}{|c|c|c|c|c|c|c|c|}
\hline Karakter & HP & EP & ATK & DEF & MAG & RES & Actions \\
\hline Knight & 120 & 45 & 15 & 30 & 5 & 25 & $\begin{array}{l}\text { Slash, } \\
\text { Guard }\end{array}$ \\
\hline Fighter & 100 & 60 & 30 & 20 & 5 & 15 & $\begin{array}{l}\text { Punch, } \\
\text { Guard }\end{array}$ \\
\hline Medic & 90 & 90 & 5 & 15 & 30 & 30 & $\begin{array}{l}\text { Heal, } \\
\text { Guard }\end{array}$ \\
\hline Wizard & 90 & 90 & 5 & 15 & 30 & 30 & $\begin{array}{l}\text { Fire, } \\
\text { Guard }\end{array}$ \\
\hline Archer & 100 & 60 & 30 & 20 & 5 & 15 & $\begin{array}{l}\text { Shoot, } \\
\text { Guard }\end{array}$ \\
\hline
\end{tabular}

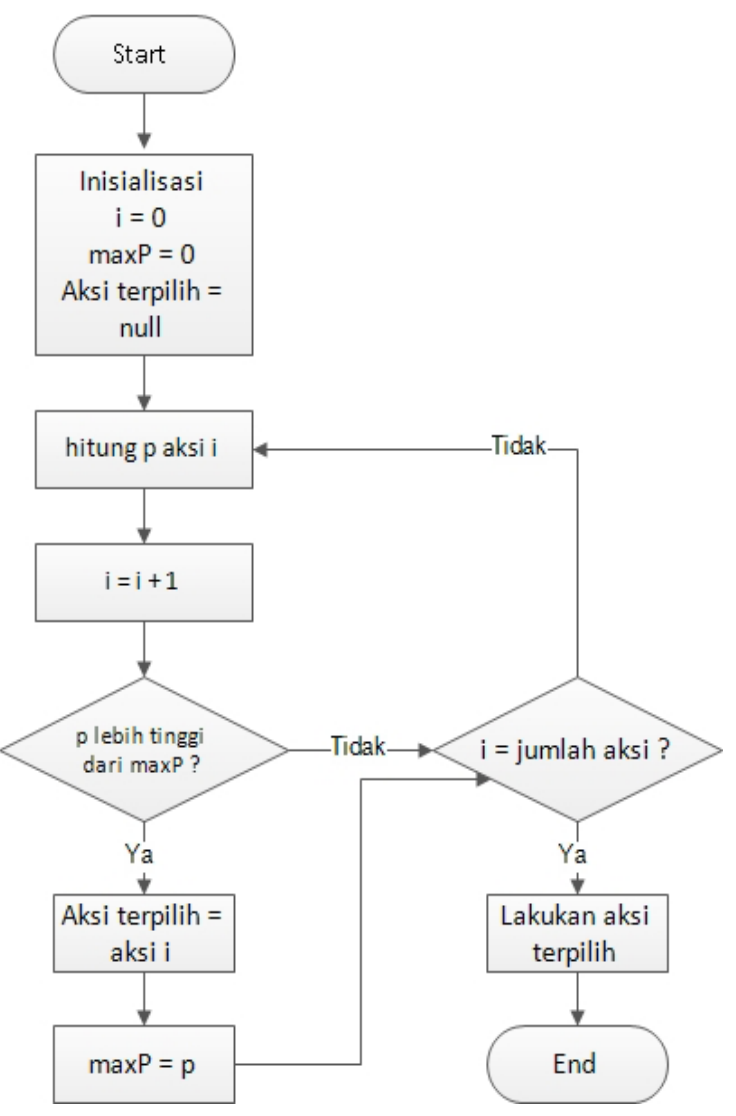

Gambar 2. Alur proses kecerdasan buatan

\section{b. Data Karakter dan Aksi}

Pada tahap ini dirancang karakter-karakter dan aksiaksi yang dapat dilakukan karakter tersebut. Desain dari karakter-karakter tersebut didasarkan pada konvensi RPG pada umumnya. Adapun game komersial yang dijadikan referensi untuk mendesain atribut-atribut karakter game ini yaitu Final Fantasy V dan Fire Emblem VII.

Pada game ini terdapat lima macam karakter, Knight, Fighter, Medic, Wizard, dan Archer. Masing-masing karakter memiliki 5 atribut yaitu Health Point (hp), Energy Point (ep) Attack (atk), Defense (def), Magic (mag), Resistance(res), dan Action. Atribut-atribut ini disajikan pada tabel 1. Adapun aksi yang dapat dilakukan oleh karakter adalah slash, puch, heal, fire, shoot, dan guard. Fungsi dari masing-masing aksi dapat dilihat pada tabel 2. Dari atribut dan aksi yang ada pada game ini maka masing-masing karakter akan memiliki kekuatan dan kelemahan masingmasing yang bersifat unik. Knight memiliki pertahanan tinggi dan serangan fisik lemah, Fighter memiliki serangan terhadap ep dan pertahanan sedang, Medic memiliki kemampuan untuk memulihkan hp, Wizard memiliki serangan mistis kuat, dan Archer memiliki serangan fisik kuat serta pertahanan sedang. Detail dari atribut dan aksi yang dimiliki karakter dapat dilihat pada tabel 3 .

Sebagian besar aksi yang dapat dilakukan oleh karakter memiliki kegunaan untuk menimbulkan damage (pengurangan nilai hp) terhadap karakter target. Masingmasing aksi memiliki rumus yang unik sebagai berikut

1. Aksi Slash

$$
\text { damage }=\left(m \times \frac{\text { actor.ath }}{\text { target.def }}+b\right) \times y
$$

2. Aksi Punch

$$
\text { damage }=\left(m \times \frac{\text { actor.atk }}{0.5 \times(\text { target. def }+ \text { target.res })}+b\right) \times y
$$

3. Aksi Heal

$$
\text { damage }=-1 \times \text { actor } m a g
$$

4. Aksi Fire

$$
\text { damage }=\left(m \times \frac{\text { actor.mag }}{\text { target.res }}+b\right) \times y
$$

5. Aksi Shoot

$$
\text { damage }=\left(m \times \frac{\text { actor.atk }}{\text { target.def }}+b\right) \times y
$$

6. Aksi Guard

$$
\begin{aligned}
& \text { target.def }=1.25 \times \text { target.def }(6) \\
& \text { target.res }=1.25 \times \text { target.res }(7)
\end{aligned}
$$

dengan:

actor.atk : Atribut atk dari karakter yang melakukan aksi.

actor.mag: Atribut mag dari karakter yang melakukan aksi.

target.def : Atribut def dari karakter yang menerima aksi.

target.res : Atribut res dari karakter yang menerima aksi. $\mathrm{m} \quad$ : Konstanta yang bernilai 0.266. Merepresentasikan derajat kemiringan fungsi linier yang digunakan sebagai rumus damage aksi.

b : Konstanta yang bernilai -0.032

y : Konstanta yang bernilai 150

\section{c. Desain Kecerdasan Buatan}

Pengambilan keputusan pada kecerdasan buatan game ini dilakukan dengan cara membandingkan nilai priority point dari setiap aksi yang mungkin. Alur berjalannya kecerdasan buatan dapat dilihat pada Gambar 2.

Pertama-tama program menginisialisasi variabel prioritas maksimum dengan nilai nol, dan aksi terpilih dengan nilai kosong. Setelah itu program akan melakukan iterasi sebanyak jumlah aksi yang mungkin. Pada setiap iterasi satu aksi akan dihitung nilai prioritasnya dan dibandingkan nilai prioritas maksimum. Jika nilai prioritasnya lebih tinggi maka aksi tersebut akan dijadikan aksi terpilih. 


\section{d. Himpunan Fuzzy}

Logika furay pada game ini merupakan inti dari sistem kecerdasan buatan secara keseluruhan. Pada tahap ini dirancang variabel-variabel fur:y. Variabel-variabel yang digunakan untuk menentukan priority (p) suatu aksi mencakup bealth point (hp), energy point (ep), dexterity, dan damage. Variabel hp dan ep diambil secara langsung dari atribut target, variabel dexterity merupakan rata-rata dari defense dan resistance target, sedangkan variabel damage dihitung menggunakan rumus penghitungan damage yang dimiliki masing-masing aksi.

Fungsi keanggotaan masing-masing variabel fur:y ditentukan dengan metode trial and error dengan pendekatan goal driven. Adapun fungsi keanggotaan tersebut adalah sebagai berikut:

1) Aksi serangan Slash, Fire, dan Shoot

Variabel damage pada aksi slash

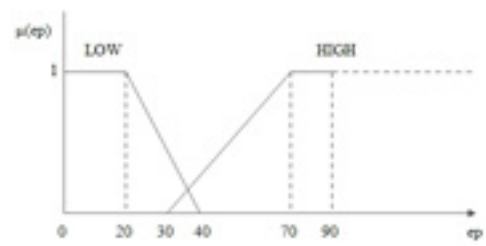

Gambar 3. Fungsi keanggotaan variabel damage pada aksi slash

Variabel damage pada aksi fire dan shoot

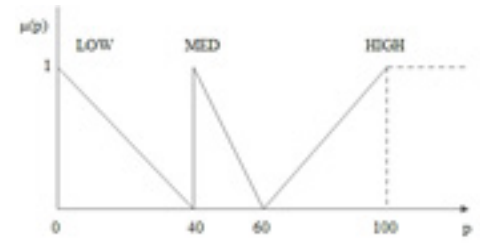

Gambar 4. Fungsi keanggotaan variabel damage pada aksifire dan shoot

Variabel hp pada aksi slash, fire, dan shoot

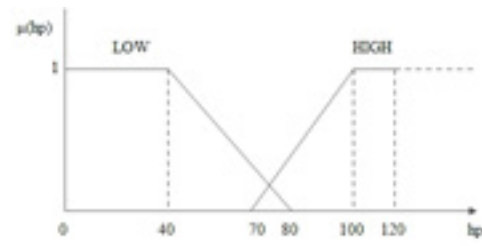

Gambar 5. Fungsi keanggotaan variabel hp pada aksi slash, fire, dan shoot

Variabel p pada aksi slash, fire, dan shoot

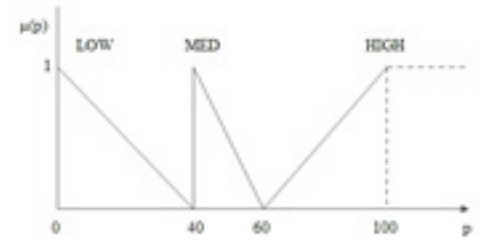

Gambar 6. Fungsi keanggotaan variabel p pada aksi slash, fire, dan shoot
2) Aksi serangan punch

Variabel damage pada aksi punch

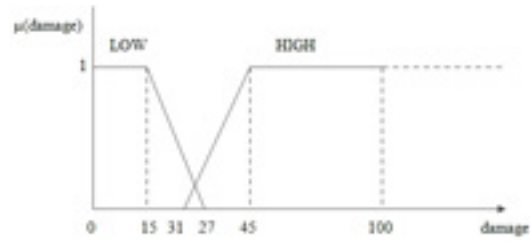

Gambar 7. Fungsi keanggotaan variabel damage pada aksi punch

Variabel ep pada aksi punch

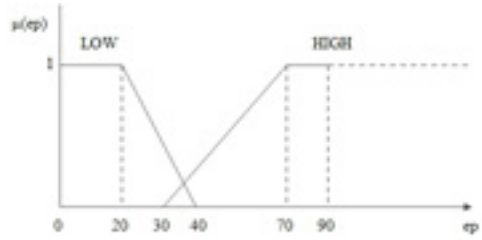

Gambar 8. Fungsi keanggotaan variabel ep pada aksi punch

Variabel p pada aksi punch

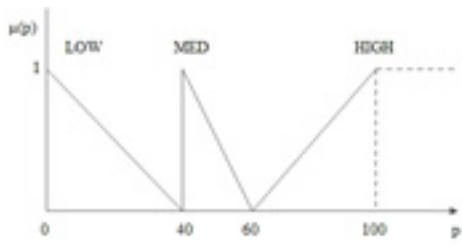

Gambar 9. Fungsi keanggotaan variabel p pada aksi punch

3) Aksi pemulihan (Heal)

Variabel dexterity pada aksi heal

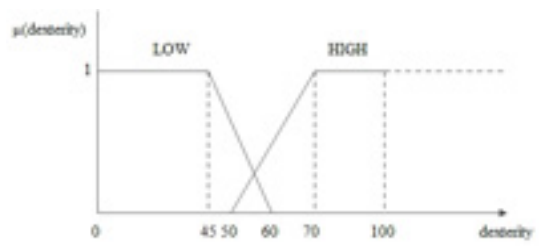

Gambar 10. Fungsi keanggotaan variabel dexterity pada aksi beal

Variabel hp pada aksi heal

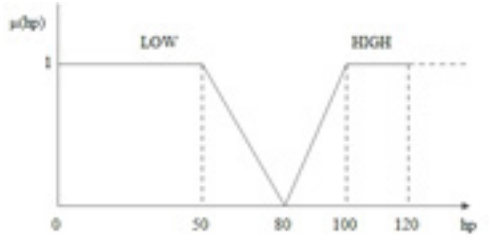

Gambar 11. Fungsi keanggotaan variabel hp pada aksi beal 
Variabel p pada aksi heal

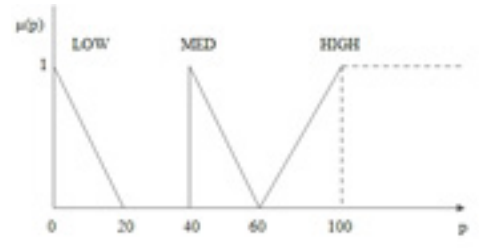

Gambar 12. Fungsi keanggotaan variabel p pada aksi beal

4) Aksi perlindungan (guard)

Variabel dexterity pada aksi guard

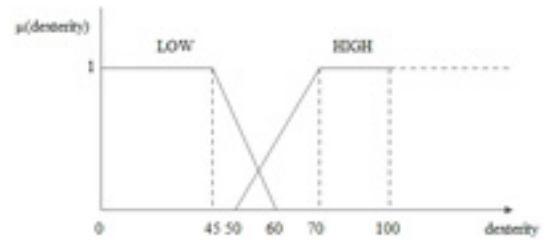

Gambar 13. Fungsi keanggotaan variabel dexterity pada aksi guard

Variabel hp pada aksi guard

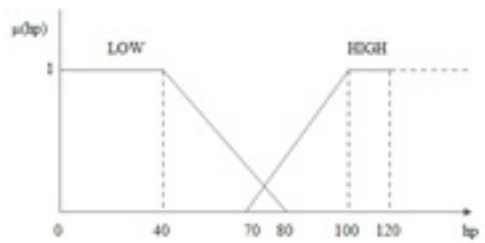

Gambar 14. Fungsi keanggotaan variabel hp pada aksi guard

Variabel p pada aksi guard

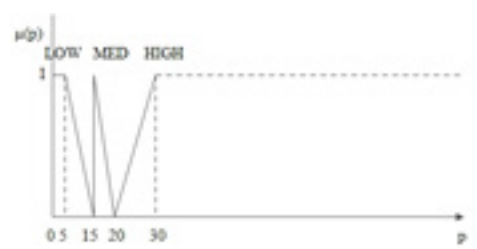

Gambar 15. Fungsi keanggotaan variabel p pada aksi guard

\section{e. Aturan Fuzzy}

Berdasarkan peraturan game dan aksi-aksi yang telah ditentukan dapat didesain furzy rules sebagai basis dari pengambilan keputusan sistem kecerdasan buatan. Seperti pada fungsi keanggotaan furzy pada bab sebelumnya, perancangan rules juga dilakukan dengan metode trial and error dengan pendekatan goal-driven. Dalam artian aksi-aksi yang paling logis untuk dipilih pada berbagai situasi telah diketahui sehingga fuzzy rules perlu dirancang sedemikian rupa agar sistem kecerdasan buatan dapat memilih aksiaksi tersebut.

Berdasarkan fuzzy rules yang digunakan, aksi dapat dikategorikan menjadi empat macam. Adapun keempat macam aksi tersebut beserta furzy rules yang digunakan adalah sebagai berikut:
1. Aksi serangan Slash, Fire, dan Shoot

Aksi Slash, Fire, dan Shoot berfungsi untuk mengurangi hp target (damage). Proses penghitungan damage dari ketiga aksi tersebut berbeda tetapi tujuannya sama. Tujuan dari kelompok aksi ini adalah untuk menimbulkan damage sebesar-besarnya atau mematikan target yang memiliki hp kecil. Sehingga furay rules yang digunakan yaitu:

a. JIKA damage HIGH ATAU hp LOW MAKA p HIGH.

b. JIKA damage HIGH DAN hp HIGH MAKA $\mathrm{p}$ MED.

c. JIKA damage LOW ATAU hp LOW MAKA p MED.

d. JIKA damage LOW ATAU hp HIGH MAKA p LOW.

2. Aksi serangan Punch

Aksi Punch berfungsi untuk mengurangi hp dan ep target. Tujuan utama dari aksi ini adalah untuk menghambat atau menghentikan target dalam melakukan aksi pada giliran selanjutnya dengan cara mengurangi ep target di samping mengurangi hp seperti aksi serangan lainnya. Sehingga fuzay rules yang digunakan yaitu:
a. JIKA damage HIGH DAN ep HIGH MAKA p HIGH.
b. JIKA damage HIGH DAN ep LOW MAKA p MED.
c. JIKA damage LOW ATAU ep HIGH MAKA p MED.
d. JIKA damage LOW DAN ep LOW MAKA p LOW.

3. Aksi pemulihan (Heal)

Aksi Heal berfungsi untuk menambah hp target. Tujuan dari aksi ini adalah untuk menyelamatkan karakter target dari kematian yang mungkin terjadi pada giliran selanjutnya. Sehingga fuz:y rules yang digunakan yaitu:

a. JIKA dexterity HIGH ATAU hp HIGH MAKA
p LOW.
b. JIKA dexterity HIGH DAN hp LOW MAKA
p HIGH.
c. JIKA dexterity LOW ATAU hp HIGH MAKA
p LOW.
d. JIKA dexterity LOW DAN hp LOW MAKA p HIGH.

4. Aksi perlindungan (Guard)

Aksi Guard berfungsi untuk menambah pertahanan target untuk satu giliran. Tujuan dari aksi ini adalah untuk mengurangi damage dari serangan lawan yang mungkin terjadi pada giliran selanjutnya. Sehingga furay rules yang digunakan yaitu:

a. JIKA dexterity HIGH DAN hp HIGH MAKA p LOW.

b. JIKA dexterity HIGH DAN hp LOW MAKA $p$ MED.

c. JIKA dexterity LOW DAN hp LOW MAKA p MED.

d. JIKA dexterity LOW DAN hp LOW MAKA p HIGH. 
Tabel 4. Pengujian karakter knight sampel default

\begin{tabular}{ccccccc}
\hline Kubu & Karakter & hp & ep & Damage & P Slash & P Guard \\
\hline \multirow{4}{*}{ Biru } & Knight & 120 & 45 & 16 & 20 & - \\
& Wizard & 90 & 90 & 36 & 40 & - \\
& Archer & 100 & 60 & 26 & 21.5 & - \\
& Knight & 120 & 45 & - & - & 9.8 \\
\multirow{4}{*}{ Merah } & Wizard & 90 & 90 & - & - & 10 \\
& Archer & 100 & 60 & - & - & 10 \\
\hline
\end{tabular}

Tabel 5. Pengujian karakter $k n i g h t$ sampel ekstrem

\begin{tabular}{ccccccc}
\hline Kubu & Karakter & hp & ep & Damage & P Slash & P Guard \\
\hline \multirow{4}{*}{ Biru } & Knight & 40 & 33 & 16 & 46.9 & - \\
& Wizard & 90 & 70 & 36 & 40 & - \\
& Archer & 100 & 45 & 26 & 21.5 & - \\
& Knight & 120 & 45 & - & - & 9.8 \\
\multirow{4}{*}{ Merah } & Wizard & 54 & 90 & - & - & 13.3 \\
& Archer & 100 & 60 & - & - & 10 \\
\hline
\end{tabular}

Tabel 6. Pengujian karakter fighter sampel default

\begin{tabular}{ccccccc}
\hline Kubu & Karakter & hp & ep & Damage & P Punch & P Guard \\
\hline \multirow{4}{*}{ Biru } & Knight & 120 & 45 & 39 & 63.8 & - \\
& Wizard & 90 & 90 & 49 & 70 & - \\
& Archer & 100 & 60 & 64 & 67.5 & - \\
& Knight & 120 & 45 & - & - & 9.8 \\
\multirow{4}{*}{ Merah } & Wizard & 90 & 90 & - & - & 10 \\
& Fighter & 100 & 60 & - & - & 10 \\
\hline
\end{tabular}

Tabel 7. Pengujian karakter fighter sampel ekstrem

\begin{tabular}{ccccccc}
\hline Kubu & Karakter & hp & ep & Damage & P Punch & P Guard \\
\hline \multirow{4}{*}{ Biru } & Knight & 40 & 33 & 39 & 63.3 & - \\
& Wizard & 8 & 21 & 49 & 51.9 & - \\
& Archer & 100 & 45 & 64 & 66.3 & - \\
& Knight & 68 & 33 & - & - & 14.5 \\
\multirow{4}{*}{ Merah } & Wizard & 54 & 70 & - & - & 13.3 \\
& Fighter & 100 & 45 & - & - & 10 \\
\hline
\end{tabular}

Tabel 8. Pengujian karakter medic sampel default

\begin{tabular}{ccccccc}
\hline Kubu & Karakter & hp & ep & Damage & P Heal & P Guard \\
\hline \multirow{4}{*}{ Biru } & Knight & 120 & 45 & - & - & - \\
& Wizard & 90 & 90 & - & - & - \\
& Archer & 100 & 60 & - & - & - \\
& Knight & 120 & 45 & -45 & 0 & 9.8 \\
\multirow{4}{*}{ Merah } & Medic & 90 & 90 & -45 & 3.3 & 10 \\
& Archer & 100 & 60 & -45 & 0 & 10 \\
\hline
\end{tabular}

Tabel 9. Pengujian karakter medic sampel ekstrrm

\begin{tabular}{ccccccc}
\hline Kubu & Karakter & hp & ep & Damage & P Heal & P Guard \\
\hline \multirow{4}{*}{ Biru } & Knight & 40 & 33 & - & - & - \\
& Wizard & 54 & 70 & - & - & - \\
& Archer & 100 & 45 & - & - & - \\
\multirow{4}{*}{ Merah } & Knight & 120 & 33 & -45 & 0 & 9.8 \\
& Medic & 90 & 90 & -45 & 3.3 & 10 \\
& Archer & 18 & 60 & -45 & 50 & 15 \\
\hline
\end{tabular}

Tabel 10. Pengujian karakter wizard sampel default

\begin{tabular}{ccccccc}
\hline Kubu & Karakter & hp & ep & Damage & P Fire & P Guard \\
\hline \multirow{4}{*}{ Biru } & Knight & 120 & 45 & 44 & 21.1 & - \\
& Wizard & 90 & 90 & 36 & 28.6 & - \\
& Archer & 100 & 60 & 75 & 46.7 & - \\
& Knight & 120 & 33 & - & - & 9.8 \\
\multirow{4}{*}{ Merah } & Wizard & 15 & 90 & - & - & 10 \\
& Archer & 100 & 60 & - & - & 10 \\
\hline
\end{tabular}

Tabel 11. Pengujian karakter wizard sampel ekstrem

\begin{tabular}{ccccccc}
\hline Kubu & Karakter & hp & ep & Damage & P Fire & P Guard \\
\hline \multirow{4}{*}{ Biru } & Knight & 60 & 33 & 44 & 58.3 & - \\
& Wizard & 90 & 70 & 36 & 54.9 & - \\
& Archer & 100 & 45 & 75 & 46.7 & - \\
& Knight & 120 & 45 & - & - & 9.8 \\
\multirow{4}{*}{ Merah } & Wizard & 54 & 90 & - & - & 15 \\
& Archer & 100 & 60 & - & - & 10 \\
\hline
\end{tabular}

\section{f. Defuzifikasi}

Defuzzifikasi pada model Fuzzy'Tsukamoto dilakukan dengan menggunakan metode rata-rata terbobot. Rata-rata terbobot dihitung berdasarkan fire strength dan nilai hasil inferensi yang telah diperoleh pada tahap sebelumnya. Pada program ini inferensi fuzzy menggunakan empat rules sehingga rumus defuzzifikasi adalah sebagai berikut:

$$
p=\frac{w_{1} z_{1}+w_{2} z_{2}+w_{3} z_{3}+w_{4} z_{4}}{w_{1}+w_{2}+w_{3}+w_{4}}
$$

Dimana

$\mathrm{p}:$ nilai prioritas hasil rata-rata terbobot

$\mathrm{z} \quad$ : nilai hasil inferensi

$\mathrm{w}$ : fire strength

Hasil akhir $p$ merupakan nilai prioritas dari aksi yang sedang dihitung. Nilai inilah yang kemudian digunakan sebagai pembanding antara satu aksi dengan lainnya.

\section{Hasil dan Pembahasan}

Pada bagian ini akan dibahas efektivitas kinerja kecerdasan buatan yang dihasilkan. Untuk itu perlu dilakukan pengujian dengan menganalisis nilai prioritas $(p)$ setiap aksi oleh satu karakter pada situasi-situasi tertentu. Dari nilai prioritas tersebut dapat dilihat aksi yang dipilih dan dianalisis apakah pemilihan aksi tersebut sudah tepat atau tidak. Tepat tidaknya suatu aksi dinilai berdasarkan nalar dengan merujuk pada peran masing-masing karakter yang telah dijabarkan sebelumnya.

Data pengujian masing-masing karakter diambil dari dua macam sampel, yaitu sampel awal dan sampel ekstrem. Sampel awal adalah data yang diambil pada saat pertarungan pertama kali dimulai. Sedangkan sampel ekstrem diambil pada saat terdapat satu karakter yang diperkirakan akan memiliki prioritas tinggi sebagai target suatu aksi, misalkan karakter musuh yang memiliki HP rendah. 
Tabel 11. Pengujian karakter archer sampel default

\begin{tabular}{ccccccc}
\hline Kubu & Karakter & hp & ep & Damage & P Shoot & P Guard \\
\hline \multirow{4}{*}{ Biru } & Knight & 120 & 45 & 36 & 15.9 & - \\
& Wizard & 90 & 90 & 75 & 60 & - \\
& Archer & 100 & 60 & 56 & 31.5 & - \\
& Knight & 120 & 45 & - & - & 9.8 \\
\multirow{4}{*}{ Merah } & Wizard & 90 & 90 & - & - & 10 \\
& Archer & 100 & 60 & - & - & 10 \\
\hline
\end{tabular}

Tabel 12. Pengujian karakter archer sampel ekstrem

\begin{tabular}{ccccccc}
\hline Kubu & Karakter & hp & ep & Damage & P Shoot & P Guard \\
\hline \multirow{4}{*}{ Biru } & Knight & 40 & 33 & 36 & 61 & - \\
& Wizard & 90 & 70 & 75 & 60 & - \\
& Archer & 100 & 45 & 56 & 31.5 & - \\
& Knight & 120 & 33 & - & - & 9.8 \\
\multirow{3}{*}{ Merah } & Wizard & 54 & 90 & - & - & 15 \\
& Archer & 100 & 60 & - & - & 10 \\
\hline
\end{tabular}

\section{a. Pengujian Karakter Knight}

Karakter Knight adalah karakter yang memiliki atribut pertahanan kuat dan serangan lemah. Peran utama karakter ini adalah untuk melakukan aksi slash terhadap karakter lawan yang lemah terhadap serangan fisik. Aksi guard hanya dilakukan pada saat karakter tidak memiliki ep yang cukup untuk melakukan serangan. Hasil pengujian ditunjukkan pada tabel 4 dan tabel 5 .

Tabel 4 menunjukkan bahwa pada saat karakter knight merah melakukan aksi pertama menghadapi musuh knight, wizard dan archer, aksi yang terpilih adalah slash terhadap wizard biru dengan nilai $\mathrm{p}=40$. Aksi tersebut memiliki prioritas tinggi karena menimbulkan damage yang paling tinggi. Tabel 5 menunjukkan bahwa pada situasi yang berbeda dengan karakter-karakter yang sama, aksi yang terpilih adalah slash terhadap karakter knight biru dengan nilai $\mathrm{p}=46.9$. Aksi tersebut terpilih karena knight biru sudah hampir mati dengan nilai ep $=40$, meskipun damage yang dihasilkan lebih kecil daripada aksi slash terhadap wizard biru. Sedangkan untuk aksi guard, prioritas tertinggi adalah terhadap karakter wizard merah dengan nilai $p$ $=13.3$, pada kasus lain saat karakter knight merah tidak memiliki ep untuk melakukan aksi slash, aksi inilah yang akan dipilih. Prinsip yang sama terhadap penggunaan aksi guard juga berlaku bagi semua karakter lainnya kecuali medic.

\section{b. Pengujian Karakter Fighter}

Karakter Fighter adalah karakter yang memiliki atribut pertahanan sedang dan serangan yang mampu mengurangi ep target. Peran utama karakter ini adalah untuk melakukan aksi punch terhadap karakter yang memiliki ep tinggi, dimaksudkan agar karakter target tidak dapat banyak melakukan aksi pada giliran-giliran selanjutnya. Aksi guard hanya dilakukan pada saat karakter tidak memiliki ep yang cukup untuk melakukan serangan. Hasil pengujian karakter fighter dapat dilihat pada tabel 6 dan tabel 7.

Tabel 6 menunjukkan bahwa pada saat karakter fighter merah melakukan aksi pertama menghadapi musuh knight, wizard, dan archer, aksi yang terpilih adalah punch terhadap wizard biru dengan nilai $\mathrm{p}=70$. Aksi tersebut memiliki prioritas tinggi karena karakter target memiliki ep yang paling tinggi sebanyak 90 point. Tabel 7 menunjukkan bahwa pada situasi yang berbeda dengan karakter-karakter yang sama, aksi yang terpilih adalah punch terhadap archer biru dengan nilai $\mathrm{p}=$ 66.3. Aksi tersebut terpilih karena archer biru memiliki nilai ep yang paling tinggi sehingga perlu dibungkam agar tidak dapat melakukan aksi pada giliran selanjutnya sebagaimana yang telah dilakukan terhadap wizard merah.

\section{c. Pengujian Karakter Medic}

Karakter Medic adalah karakter yang memiliki atribut pertahanan lemah dan aksi yang mampu memulihkan hp karakter kawan atau diri sendiri. Peran utama karakter ini adalah untuk memulihkan hp karakter kawan yang telah berkurang akibat serangan musuh dengan aksi heal. Aksi guard dilakukan pada saat tidak ada karakter kawan yang memerlukan pemulihan hp. Hasil pengujian terhadap karakter medic ini ditunjukkan pada tabel 8 dan tabel 9 .

Tabel 8 menunjukkan bahwa pada saat karakter medic merah melakukan aksi pertama dengan karakter kawan knight dan archer, aksi yang terpilih adalah guard terhadap diri sendiri dengan nilai $\mathrm{p}=10$. Aksi tersebut didahulukan atas aksi guard terhadap archer dengan nilai $\mathrm{p}$ yang sama karena pada iterasi program karakter medic merah dicek lebih awal. Dapat dilihat juga bahwa aksi heal memiliki prioritas yang sangat kecil atau pun nol terhadap karakter manapun dikarenakan hp setiap karakter masih penuh.

Tabel 9 menunjukkan bahwa pada situasi yang berbeda dengan karakter-karakter yang sama, aksi yang terpilih adalah heal terhadap archer merah dengan nilai $\mathrm{p}$ $=50$. Aksi tersebut terpilih karena archer merah hampir mati dan memerlukan bantuan pemulihan hp.

\section{d. Pengujian Karakter Wizard}

Karakter Wizard adalah karakter yang memiliki atribut pertahanan lemah dan serangan mistis kuat. Peran utama karakter ini adalah untuk melakukan aksi fire terhadap karakter lawan yang lemah terhadap serangan mistis. Aksi guard hanya dilakukan pada saat karakter tidak memiliki ep yang cukup untuk melakukan serangan.

Pengujian terhadap karakter wizard dapat dilihat pada tabel 10 dan tabel 11.

Tabel 10 menunjukkan bahwa pada saat karakter wizard merah melakukan aksi pertama menghadapi musuh knight, wizard dan archer, aksi yang terpilih adalah fire terhadap archer biru dengan nilai $\mathrm{p}=46.7$. Sedangkan tabel 11 menunjukkan bahwa pada situasi yang berbeda dengan karakter-karakter yang sama, aksi yang terpilih adalah fire terhadap karakter knight biru dengan nilai $\mathrm{p}$ $=$ 58.3. Aksi tersebut terpilih karena knight biru sudah hampir mati dengan nilai hp $=60$, meskipun damage yang dihasilkan lebih kecil daripada aksi fire terhadap archer biru.

\section{e. Pengujian Karakter Archer}

Karakter Archer adalah karakter yang memiliki atribut pertahanan sedang dan serangan fisik kuat. Peran utama karakter ini adalah untuk melakukan aksi shoot terhadap karakter lawan yang lemah terhadap serangan fisik. Aksi guard hanya dilakukan pada saat karakter tidak memiliki ep yang cukup untuk melakukan serangan. Hasil pengujian dapat dilihat pada tabel 12 dan tabel 13.

Tabel 12 menunjukkan bahwa pada saat karakter archer merah melakukan aksi pertama menghadapi musuh knight, wizard, dan archer, aksi yang terpilih adalah shoot 
terhadap wizard biru dengan nilai $\mathrm{p}=60$. Aksi tersebut memiliki prioritas tinggi karena menimbulkan damage yang paling tinggi.

Sedangkan pada situasi yang berbeda dengan karakterkarakter yang sama sebagaimana ditunjukkan tabel 13, aksi yang terpilih adalah shoot terhadap karakter knight biru dengan nilai $\mathrm{p}=61$. Aksi tersebut terpilih karena knight biru sudah hampir mati dengan nilai $\mathrm{hp}=40$, meskipun damage yang dihasilkan lebih kecil daripada aksi shoot terhadap wizard biru.

\section{f. Analisis Pengujian}

Berdasarkan hasil uji yang telah dijabarkan, dapat diamati bahwa sistem furay yang dirancang dengan pendekatan goal-driven dapat menghasilkan nilai keluaran yang diinginkan. Untuk karakter-karakter penyerang, knight, wizard, dan archer, behavior yang diinginkan dapat dicapai dengan memastikan nilai $p$ dari aksi serangan harus selalu lebih tinggi dari nilai $p$ aksi guard. Selanjutnya agar aksi serangan tersebut, diarahkan terhadap target yang tepat, maka perlu keseimbangan pembobotan antara pengaruh variabel damage dan hp target. Pada state awal permainan, variabel damage-lah yang lebih berperan dalam menentukan pemilihan serangan, sebagaimana yang ditunjukkan pada Tabel 4, Tabel 10, dan Tabel 12. Sedangkan jika ada satu karakter musuh memiliki hp dengan nilai ekstrem rendah, variabel hp-lah yang lebih berperan dalam menentukan pemilihan serangan, sebagaimana yang ditunjukkan pada Tabel 5, Tabel 11, dan Tabel 13.

Untuk karakter fighter, nilai $\mathrm{p}$ aksi punch dipengaruhi oleh variabel damage dan ep. Dapat dilihat bahwa pada semua kasus variabel ep-lah yang lebih berperan dalam menentukan aksi yang terpilih sebagaimana yang ditunjukkan pada Tabel 4 dan Tabel 5. Variabel damage berperan sebagai pembeda pada kasus saat ada dua karakter yang memiliki nilai ep berdekatan Selanjutnya untuk karakter medic yang cenderung lebih sering menggunakan aksi guard, aksi heal perlu didesain agar nilai p-nya selalu lebih rendah daripada aksi guard pada saat karakter target masih memiliki hp penuh. Nilai $p$ aksi heal akan naik secara drastis melampaui nilai $p$ maksimum aksi guard jika ada karakter yang telah berkurang hp-nya.

\section{Kesimpulan}

Dari hasil uji kinerja sistem cerdas pengimplementasian furay Tsukamoto didapatkan bahwa semua karakter telah menunjukkan behavior sesuai dengan perannya masingmasing. Semua karakter mampu memutuskan aksi yang tepat sesuai dengan kondisi lawan yang dihadapi. Dengan demikian diambil kesimpulan bahwa dengan diimplementasikannya logika Fuzzy Tsukamoto dihasilkan sistem kecerdasan buatan yang mampu menangani setiap kombinasi karakter dan setiap range situasi yang dapat ditemui pada jalannya permainan.

\section{Daftar Pustaka}

[1] A. Drachen, M. Copier, M. Hitchens, M. Montola, M. P. Eladhari, and J. Stenros, "Role-Playing Games: The State of Knowledge," Break. New Gr. Innov. Games, Play. Pract. Theory. Proc. DiGRA 2009, 2009.

[2] M. Hitchens, A. Drachen, and others, "The many faces of role-playing games," Int. J. role-playing, vol. 1, no. 1, pp. 3-21, 2008.

[3] J. Pulkkinen, "Design Values of Digital RolePlaying Games," no. April, 2014.

[4] J. H. Lee, N. Karlova, R. I. Clarke, and K. Thornton, "Facet Analysis of Video Game Genres," iConference 2014 Proc., 2014.

[5] A. S, S. L. H, and P. Gonz, "Game AI for a Turnbased Strategy Game with Plan Adaptation and AI Planning," Proceeding DIMEA '08 Proc. 3rd Int. Conf. Digit. Interact. Media Entertain. Arts, no. 0642882, pp. 295-302, 2008.

[6] U. Kose, "Developing a Fuzzy Logic Based Game System," Comput. Technol. Appl., vol. 3, no. Game Development, pp. 510-517, 2012.

[7] M. Pirovano, I. Elettronica, and P. Milano, "The use of Fuzzy Logic for Artificial Intelligence in Games The current state of Game AI," 2012.

[8] A. Shaout, B. King, and L. Reisner, "Real-Time Game Design of Pac-Man Using Fuzzy Logic," Int. Arab J. Inf. Technol., vol. 3, no. 4, pp. 315-325, 2006.

[9] Yifan Li, P. Musilek, and L. Wyard-Scott, "Fuzzy logic in agent-based game design," IEEE Annu. Meet. Furay Information, 2004. Process. NAFIPS '04., p. 734-739 Vol.2, 2004.

[10] P. Tozour, "The Evolution of Game AI," Ai Game Program. Wisdom, vol. 1, pp. 3-15, 2002.

[11] A. Saepullah and S. W. Romi, "Comparative Analysis of Mamdani, Sugeno And Tsukamoto Method of Fuzzy Inference System for Air Conditioner Energy Saving," J. Intell. Syst., vol. 1, no. 2, pp. 143-147, 2015.

[12] A. Maseleno and M. Hasan, "Finding Kicking Range of Sepak Takraw Game A Fuzzy Logic Approach _ Maseleno _ TELKOMNIKA Indonesian Journal of Electrical Engineering FT,” vol. 14, no. 3, pp. 557-564, 2015.

[13] Y. A. Gerhana et al., "Decision support system for football player' s position with tsukamoto fuzzy inference system," Aasec, vol. 03014, pp. 1-6, 2018. 